\title{
The Efficacy of Podophyllin Cautery Added to Surgical Excision for Eradication of Vulvar Condylomata Accuminata; Randomized Controlled Trial
}

\author{
Hussein 0. Soliman ${ }^{1 *}$, Yossra Lashin ${ }^{2}$ \\ ${ }^{1}$ Department of Surgical Oncology, National Cancer Institute, Cairo University, Giza, Egypt \\ ${ }^{2}$ Department of Gynecology and Obstetrics, Faculty of Medicine, Cairo University, Giza, Egypt \\ Email: *soliman@daad-alumni.de
}

How to cite this paper: Soliman, H.O. and Lashin, Y. (2018) The Efficacy of Podophyllin Cautery Added to Surgical Excision for Eradication of Vulvar Condylomata Accuminata; Randomized Controlled Trial. Journal of Cancer Therapy, 9, 559-567. https://doi.org/10.4236/jct.2018.97047

Received: June 13, 2018

Accepted: July 7, 2018

Published: July 10, 2018

Copyright $\odot 2018$ by authors and Scientific Research Publishing Inc. This work is licensed under the Creative Commons Attribution International License (CC BY 4.0).

http://creativecommons.org/licenses/by/4.0/ (c) (i) Open Access

\begin{abstract}
Context: Condyloma acuminatum is a common morbidity caused by human papillomavirus infection. Objective: To compare the recurrence rate after surgical excision with or without podophyllin cautery. Design, Setting, Participants: Sixty women were enrolled in a study that was conducted in Cairo from Jan-2017 to Mar-2018. Interventions: All women received the same preparations. After randomization; in the study group $(\mathrm{N}=30)$, podophyllin cautery was added to surgical removal in the follow-up period. In the control group $(\mathrm{N}=30)$, only surgical removal was used. Main Outcome Measure: The main outcome measure was the estimation of the recurrence of the lesion during the follow-up period. The secondary outcome measures were the incidence of adverse events. Results: Both groups were comparable ( $\mathrm{p}$-value $>$ $0.05)$ with regard to the age and BMI. Recurrence was significantly lower $(\mathrm{P}=$ 0.001 ) in the study group than the control group. In the study group, five cases (17.2\%) have recurrence whereas, in the control group, $18(60.0 \%)$ had suffered recurrence. The ARR was 42.8\% (CI 95\%: 18\% - 60.9\%) with RR of 0.29 (CI 95\%: 0.12\% - 0.67\%) and NNT2 (CI 95\%: 6\% - 2\%). During the follow-up period, 19 cases $(65.5 \%)$ of the study group experienced pain versus only eight cases $(26.7 \%)$ in the control group ( $\mathrm{p}=0.003$ ). However, the development of scars was less in the study group $7(24.1 \%)$ than in the control group 19 $(63.3 \%)$, ( $p=0.002)$. Conclusion: Podophyllin cautery, when added to surgical removal, is effective in decreasing the incidence recurrence in cases with condylomata acuminata.
\end{abstract}

\section{Keywords}

Condyloma Acuminatum, Recurrence, Adverse Events, Podophyllin Cautery, 
Surgical Excision

\section{Introduction}

The anogenital wart, condyloma acuminatum (CA) is caused by human papillomavirus (HPV) infection. Symptomatic genital warts are seen in at least $1 \%$ of the age group of $15-49$ years [1] [2] with about $50 \%$ or less being infected with HPV at some point in their lifetime [3].

Genital warts have psychological and physical impacts on patients. Despite that warts are often asymptomatic; at sometimes they can cause itching, burning, pain, irritation, or bleeding especially during sexual activity [3].

According to the 2012 European guideline for the management of anogenital warts, the treatment for CA range from self-application of topical agents like podophyllotoxin $(0.15 \%$ cream or $0.5 \%$ solution) and imiquimod ( $5 \% \mathrm{cream})$ to clinic-based therapies like cryotherapy, trichloroacetic acid, electrosurgery, scissors excision, curettage or laser therapy. Formal surgery is reserved for large warts. There is no evidence that one type of therapy is significantly superior to another one or even appropriate for all types of warts. The data confirms that only surgical therapies have primary clearance rate approaching $100 \%$ and that recurrence occurs after all treatments with a rate of $20 \%-30 \%$ or more. All therapies are associated with local skin reactions including itching, burning, erosions, and pain [4].

To the best of our knowledge, there is only one published research study that studied the effect of adding podophyllin cautery to surgical excision for the eradication of vulvar CA. Thus, the rationale which intended for this parallel randomized controlled study was to test the hypothesis that adding podophyllin cautery to surgical excision will decrease the recurrence rate of CA more than surgical removal only.

\section{Materials and Methods}

\subsection{Study Design}

This controlled, randomized, and parallel trial was conducted in Cairo University Hospital and two private centers, Cairo, Egypt during the period January 2017 to March 2018. The study conformed to the Declaration of Helsinki principles and following the Medical Research Involving Human Subjects Act. The Bio-Medical Research Ethics Committee approved it at Cairo University. The purpose of the study was explained in simple and lay Arabic language to all women before their enrollment to the study, and an informed consent form was signed by and obtained from all those enrolled.

Women meeting all of the following criteria were considered for enrollment: aged 20 - 40 years, normal BMI, sexually active, married with vulvar condylomata accuminata coming to the centers during the period of the study. 
Women presenting with any of the following were excluded from the study: previous history of infection with HPV, current history of other sexually transmitted diseases or pregnancy.

\subsection{Randomization and Blinding}

Before the trial, computer-generated randomization schedules were generated and placed in sequentially numbered sealed opaque envelopes.

Block randomization with a block size of 4 was used with 1:1 ratio of both groups (study and control groups). Recruitment was made before revealing the allocation. Sealed opaque envelope method was used for the allocation. The allocation was blind to both recruiter and participant.

\subsection{Interventions in Both Groups}

The two groups were subjected to the same preparation. For all women in both the study and the control groups, surgical excision of the wart with scalpel was made. During the follow-up period (12 weeks) podophyllin cautery with podophyllin $0.5 \%$ solutionwas made once per week only for the study group only (30 women). All women were followed up every week for the entire follow-up period.

\subsection{Procedures}

All women were subjected to detailed history (gyencologic, medical, and surgical), complete general examination to exclude the presence of any disorders. Gynecologic examinations were made systematically according to the centre's protocol.

All surgeries were done under local anaesthesia. All women were followed up postoperatively for 24-hours then dismissed.

\subsection{Outcome Measures}

The primary outcome measure was the incidence of recurrence of the lesion in both groups during the follow-up period. The secondary outcome measure was the incidence of side effects the follow-up period.

\subsection{Statistical Analysis}

Sample size calculation suggested that a minimum of 28 subjects per group is required to detect $12 \%$ difference in incidence of postoperative bleeding between groups with a standard deviation of $1.56 \%$ (taking type I or $\alpha$ error of $5 \%$, type II or $\beta$ error of $20 \%$ ). The $12 \%$ difference was based on a pilot study on 20 participants, 10 in each group. We decided to include 30 patients per group to allow for dropouts.

All statistical analyses were made by the intention to treat analysis method. All statistical tests were made using a significance level of $95 \%$. P-value $<0.05$ was considered statistically significant. SPSS software (version 20.0, SSPS Inc., Chi- 
cago, IL, USA) was used for the statistical analyses. Data were presented as (mean $\pm \mathrm{SD}$ ) for continuous variables and as frequency and percent for categorical variables. Comparisons between groups were made using Chi-square test for categorical variable and the independent t-test for the continuous variables. For the analysis of the primary outcome variable, we calculated the relative risk (RR) with $95 \%$ confidence interval, the absolute risk reduction (ARR), the relative risk reduction (RRR) and the number needed to treat (NNT).

\section{Results}

Ninety-five (95) women with CA who came to the centers were asked to participate in the study. Eight women declined to participate, and 27 women did not meet the inclusion criteria (10 due to pregnancy and 17 were out of the age range), leaving 60 eligible for randomization with 30assigned to each group. One woman lost follow up and excluded from the per-protocol analysis. The dispositions of these women are shown in Figure 1.

\subsection{Baseline Characteristics}

Both the study and the control groups were comparable with regard their baseline characteristics. There was no statistically significant difference $(p>0.05)$ between the two groups regarding the age and BMI, as shown in Table 1.

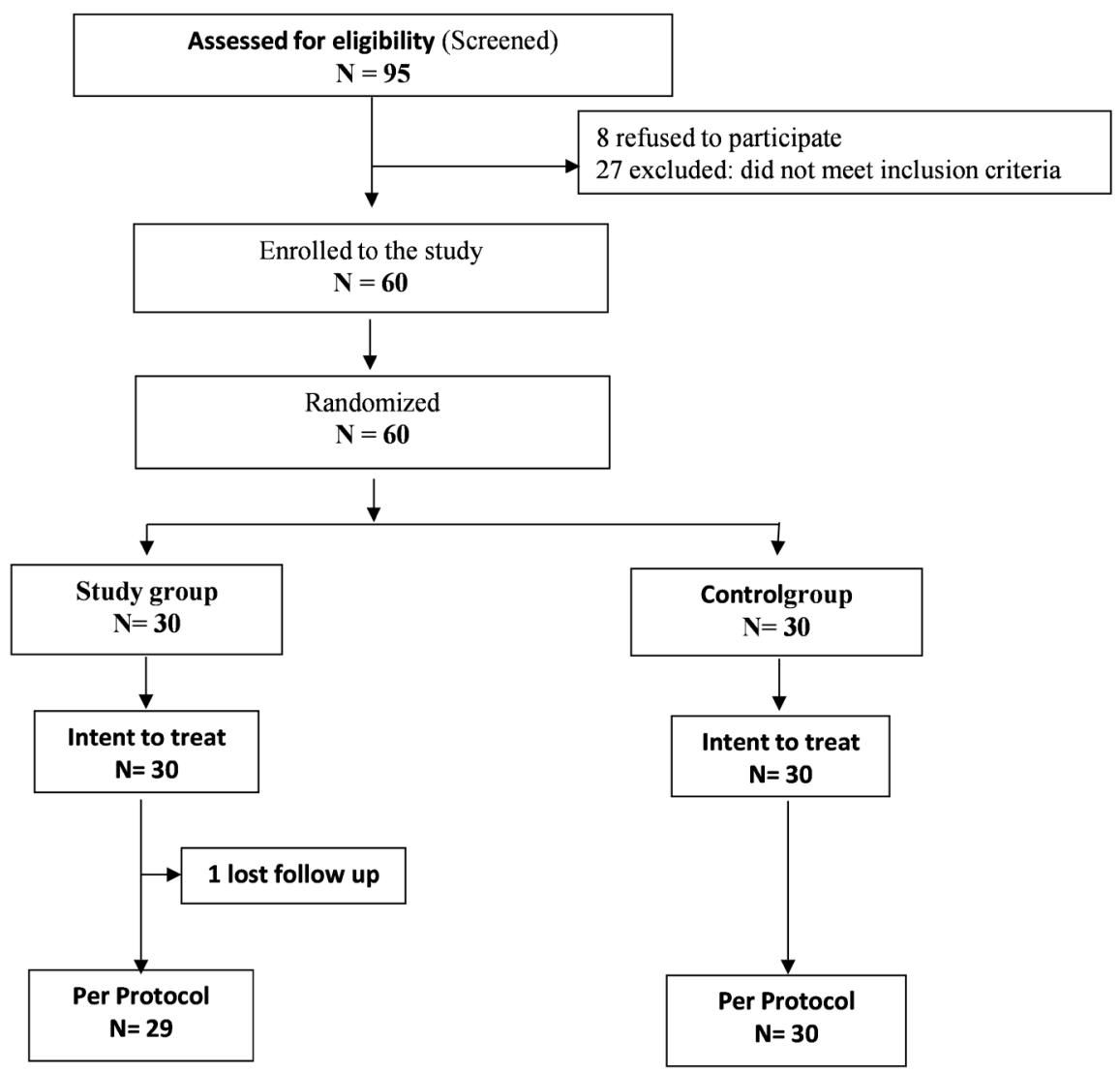

Figure 1. Consort diagram. 
Table 1. Patients' characteristics.

\begin{tabular}{cccc}
\hline & $\begin{array}{c}\text { Study group } \\
\mathbf{N}=\mathbf{3 0}\end{array}$ & $\begin{array}{c}\text { Control group } \\
\mathbf{N}=\mathbf{3 0}\end{array}$ & p-value \\
\hline Age in years & $29.60(6.17)$ & $29.60(6.17)$ & 0.976 \\
BMI $\left(\mathrm{kg} / \mathrm{m}^{2}\right)$ & $22.00(1.37)$ & $21.62(1.36)$ & 0.289 \\
\hline
\end{tabular}

\subsection{Study Outcomes}

During the follow-up period, 19 cases (65.5\%) of the study group experienced pain versus only eight cases $(26.7 \%)$ in the control group $(\mathrm{p}=0.003)$. However, the development of scars was less in the study group $7(24.1 \%)$ than in the control group 19 (63.3\%), ( $\mathrm{p}=0.002)$.

Recurrence of the lesion was significantly lower $(\mathrm{p}=0.001)$ in the study group than the control group. In the study group, five cases (17.2\%) have recurrence whereas, in the control group, 18 (60.0\%) had suffered recurrence. The ARR was 42.8\% (CI 95\%: $18 \%-60.9 \%$ ) with RR of $0.29 \%$ (CI 95\%: 0.12\% - 0.67\%) and number needed to treat (NNT) 2\% (CI 95\%: 6\% - 2\%), as shown in Table 2.

\section{Discussion}

Because of the high rate of recurrence of CA after any modality of treatment (20\% - 30\% or more) [4], researchers have to seek for more methods or combination of methods to reduce this high rate. This randomized controlled study was conducted to test the hypothesis that adding podophyllin cautery to surgical excision will decrease the recurrence rate of CA more than surgical removal only in cases with CA.

It was quite evident from this study that adding podophyllin cautery to surgical excision will further reduce the recurrence rate of CA where the ARR was 42.8\% (CI 95\%: 18\% - 60.9\%) with RR of 0.29\% (CI 95\%: 0.12\% - 0.67\%) and NNT 2\% (CI 95\%: 6\% - 2\%). Furthermore, the development of scars was lower in the study group than in the control group. However, during the follow-up period, pain was experienced more in the study group than in the control group.

According to the results of randomized clinical trials, data suggested that podophyllin resin is more effective than placebo and that, surgical treatments are largely equivalent [5].

The antimitotic agent, podophyllin resin, one of the oldest nonsurgical treatments available for CA, destroys warts by inducing tissue necrosis locally. It is used compounded as a $10 \%-25 \%$ suspension in tincture benzoin [6] [7].

The extensive evaluation of efficacy [5] [6] [7] and safety of podophyllin resin showed that despite its efficacy, a variety of adverse effects including suppression of bone marrow, liver cell dysfunction, neuropsychological symptoms and gastrointestinal disturbance, and acute abdominal pain have been reported [8]-[20]. The recurrence rate after using podophyllin alone has been reported to be $65 \%$ of cases [21]-[26]. Due to the availability of a large number of alternative modalities of treatment and these reports of side effects, some European 
Table 2. Treatment outcome.

\begin{tabular}{cccc}
\hline & $\begin{array}{c}\text { Study group } \\
\mathbf{N = 2 9}\end{array}$ & $\begin{array}{c}\text { Control group } \\
\mathbf{N}=\mathbf{3 0}\end{array}$ & p-value \\
\hline Pain & $19(65.5 \%)$ & $8(26.7 \%)$ & $\mathbf{0 . 0 0 3}$ \\
Scar & $7(24.1 \%)$ & $19(63.3 \%)$ & $\mathbf{0 . 0 0 2}$ \\
Recurrence & $5(17.2 \%)$ & $18(60.0 \%)$ & $\mathbf{0 . 0 0 1}$ \\
Relative risk (RR) & $0.29(0.12$ to 0.67$)$ \\
Relative risk reduction (RRR) & \multicolumn{3}{c}{$71 \%(32.8 \%-87.7 \%)$} \\
Absolute risk reduction (ARR) & \multicolumn{3}{c}{$42.8 \%(18 \%-60.9 \%)$} \\
Number needed to treat (NNT) & \multicolumn{3}{c}{$2(6-2)$} \\
\hline
\end{tabular}

experts recommended against its use in the primary-care settings especially in large dose over an extensive area of skin surfaces which favored systemic absorption [8]. In the current study, we used podophyllin in lower frequency to avoid the adverse events.

Surgical removal by scalpel directly removes wart-affected tissues. Clinical research studies reported that $35 \%-100 \%$ of cases showed clearance of visible warts immediately with recurrence rate of $19 \%-29 \%$ one year after excision [4] [27] [28]. Podophyllin alone appears to be less effective than surgical excision [27] [28] [29].

The evidence of the current study is fairly strong to prove that adding podophyllin cautery to surgical excision will decrease the recurrence rate of CA more than surgical removal only in cases with CA. Also, adding podophyllin cautery to surgical excision is safe.

\section{Conclusion}

Podophyllin cautery, when added to surgical removal, is effective in decreasing the incidence recurrence in cases with CA. Also, this combination is safe for those cases on the long run.

\section{Compliance with Ethical Standards}

\section{Declaration of Interest}

All authors declare that there is no conflict of interest that could be perceived as prejudicing the impartiality of the research reported.

\section{Ethical Approval}

All procedures performed in studies involving human participants were in accordance with the ethical standards of the institutional and/or national research bioethical committee and with the 1964 Helsinki declaration and its later amendments or comparable ethical standards.

\section{Informed Consent}

Informed consent was obtained from all individual participants included in the 
study.

\section{Declaration of Conflict of Interests}

All authors have no things to disclose.

\section{Funding}

This research did not receive any specific grant from any funding agency in the public, commercial or not-for-profit sector.

\section{Acknowledgements}

We would like to acknowledge Dr. Emad R.H. Issak (ClinAmygate) for his efforts in statistical analysis and editing of this manuscript.

\section{References}

[1] Gall, S.A. (2001) Female Genital Warts: Global Trends and Treatments. Infectious Diseases in Obstetrics and Gynecology, 9, 149-154. https://doi.org/10.1155/S1064744901000278

[2] Money, D.M. and Roy, M. (2007) Canadian Consensus Guidelines on Human Papillomavirus. Journal of Obstetrics and Gynaecology Canada, 29, S1-S56. https://doi.org/10.1016/S1701-2163(16)32573-7

[3] Workowski, K.A. and Berman, S. (2010) Centers for Disease Control and Prevention Sexually Transmitted Diseases Treatment Guidelines. MMWR Recommendations and Reports, 59, 1-110.

[4] Lacey, C., Woodhall, S., Wikström, A. and Ross, J. (2013) 2012 European Guideline for the Management of Anogenital Warts. Journal of the European Academy of Dermatology and Venereology, 27, e263-e270. https://doi.org/10.1111/j.1468-3083.2012.04493.x

[5] Wiley, D.J. and Beutner, K.R. (2000) Genital Warts. Clinical Evidence, 3, 764-774.

[6] Beutner, K.R., Wiley, D.J., Douglas, J.M., Tyring, S.K., Fife, K., Trofatter, K. and Stone, K.M. (1999) Genital Warts and Their Treatment. Clinical Infectious Diseases, 28, S37-S56. https://doi.org/10.1086/514722

[7] Beutner, K.R., Richwald, G.A., Wiley, D.J., Reitano, M.V. and AMA Expert Panel on External Genital Warts (1998) External Genital Warts: Report of the American Medical Association Consensus Conference. Clinical Infectious Diseases, 27, 796-806. https://doi.org/10.1086/514964

[8] von Krogh, G., Lacey, C.J., Gross, G., Barrasso, R. and Schneider, A. (2000) European Course on HPV Associated Pathology: Guidelines for Primary Care Physicians for the Diagnosis and Management of Anogenital Warts. Sexually Transmitted Infections, 76, 162-168. https://doi.org/10.1136/sti.76.3.162

[9] Cassidy, D.E., Drewry, J. and Fanning, J.P. (1982) Podophyllum Toxicity: A Report of a Fatal Case and a Review of the Literature. Journal of Toxicology: Clinical Toxicology, 19, 35-44. https://doi.org/10.3109/15563658208990364

[10] Tyring, S.K., Arany, I., Stanley, M.A., et al. (1998) A Randomized, Controlled, Molecular Study of Condylomata Acuminata Clearance during Treatment with Imiquimod. The Journal of Infectious Diseases, 178, 551-555.

https://doi.org/10.1086/517472 
[11] Leslie, K.O. and Shitamoto, B. (1982) The Bone Marrow in Systemic Podophyllin Toxicity. American Journal of Clinical Pathology, 77, 478-480. https://doi.org/10.1093/ajcp/77.4.478

[12] Filley, C.M., Graff-Richard, N.R., Lacy, J.R., Heitner, M.A. and Earnest, M.P. (1982) Neurologic Manifestations of Podophyllin Toxicity. Neurology, 32, 308-311. https://doi.org/10.1212/WNL.32.3.308

[13] Boillot, A., Cordier, A., Guerault, E., et al. (1989) A Rare Case of Severe Toxic Peripheral Neuropathy: Poisoning by Podophyllin. Apropos of 1 Case. Journal de Toxicologie Clinique et Experimentale, 9, 409-412.

[14] Gorin, F., Kindall, D. and Seyal, M. (1989) Dorsal Radiculopathy Resulting from Podophyllin Toxicity. Neurology, 39, 607-608. https://doi.org/10.1212/WNL.39.4.607

[15] Yang, C.M., Deng, J.F., Chen, C.F. and Chang, L.W. (1994) Experimental Podophyllotoxin (Bajiaolian) Poisoning: III. Biochemical Bases for Toxic Effects. Biomedical and Environmental Sciences, 7, 259-265.

[16] Kao, W.F., Hung, D.Z., Tsai, W.J., Lin, K.P. and Deng, J.F. (1992) Podophyllotoxin Intoxication: Toxic Effect of Bajiaolian in Herbal Therapeutics. Human \& Experimental Toxicology, 11, 480-487. https://doi.org/10.1177/096032719201100607

[17] Tomczak, R.L. and Hake, D.H. (1992) Near Fatal Systemic Toxicity from Local Injection of Podophyllin for Pedal Verrucae Treatment. The Journal of Foot Surgery, $31,36-42$.

[18] Chan, Y.W. (1991) Magnetic Resonance Imaging in Toxic Encephalopathy Due to Podophyllin Poisoning. Neuroradiology, 33, 372-373.

https://doi.org/10.1007/BF00587830

[19] Conard, P.F., Hanna, N., Rosenblum, M. and Gross, J.B. (1990) Delayed Recognition of Podophyllum Toxicity in a Patient Receiving Epidural Morphine. Anesthesia \& Analgesia, 71, 191-193. https://doi.org/10.1213/00000539-199008000-00013

[20] Oliveira, A.S., Calia, L.C., Kiyomoto, B.H., Povoa, E.F., Schmidt, B. and Gabbai, A.A. (1996) Acute Necrotizing Myopathy and Podophyllin Toxicity: Report of a Fatal Case. Arquivos de Neuro-Psiquiatria, 54, 288-292. https://doi.org/10.1590/S0004-282X1996000200017

[21] Douglas, J.M., Eron, L.J., Judson, F.N., et al. (1990) A Randomized Trial of Combination Therapy with Intralesional Interferon $\alpha 2 \mathrm{~b}$ and Podophyllin versus Podophyllin Alone for the Therapy of Anogenital Warts. The Journal of Infectious Diseases, 162, 52-59. https://doi.org/10.1093/infdis/162.1.52

[22] Edwards, A., Atma-Ram, A. and Thin, R.N. (1988) Podophyllotoxin 0.5\% v Podophyllin 20\% to Treat Penile Warts. Genitourinary Medicine, 64, 263-265. https://doi.org/10.1136/sti.64.4.263

[23] Gabriel, G. and Thin, R.N. (1983) Treatment of Anogenital Warts. Comparison of Trichloracetic Acid and Podophyllin versus Podophyllin Alone. The British Journal of Venereal Diseases, 59, 124-126. https://doi.org/10.1136/sti.59.2.124

[24] Hellberg, D., Svarrer, T., Nilsson, S. and Valentin, J. (1995) Self-Treatment of Female External Genital Warts with 0.5\% Podophyllotoxin Cream (Condyline) vs. Weekly Applications of 20\% Podophyllin Solution. International Journal of STD \& AIDS, 6, 257-261. https://doi.org/10.1177/095646249500600407

[25] Kinghorn, G.R., McMillan, A., Mulcahy, F., Drake, S., Lacey, C. and Bingham, J.S. (1993) An Open, Comparative, Study of the Efficacy of 0.5\% Podophyllotoxin Lotion and 25\% Podophyllotoxin Solution in the Treatment of Condylomataacumina- 
ta in Males and Females. International Journal of STD \& AIDS, 4, 194-199. https://doi.org/10.1177/095646249300400403

[26] Lassus, A., Haukka, K. and Forsstrom, S. (1984) Podophyllotoxin for Treatment of Genital Warts in Males: A Comparison with Conventional Podophyllin Therapy. European Journal of Sexually Transmitted Diseases, 2, 31-33.

[27] Jensen, S.L. (1985) Comparison of Podophyllin Application with Simple Surgical Excision in Clearance and Recurrence of Perianal Condylomataacuminata. The Lancet, 2, 1146-1148. https://doi.org/10.1016/S0140-6736(85)92677-7

[28] Khawaja, H.T. (1989) Podophyllin versus Scissor Excision in the Treatment of Perianal Condylomataacuminata: A Prospective Study. British Journal of Surgery, 76, 1067-1068. https://doi.org/10.1002/bjs.1800761027

[29] Duus, B.R., Philipsen, T., Christensen, J.D., Lundvall, F. and Sondergaard, J. (1985) Refractory Condylomataacuminata: A Controlled Clinical Trial of Carbon Dioxide Laser versus Conventional Surgical Treatment. Genitourinary Medicine, 61, 59-61. 